Maria Auxiliadora de B. L.

DAL MONTE'

Roberto Germano Costa ${ }^{2}$

Marinei GROTTA ${ }^{3}$

Gerson Bragagnoli ${ }^{4}$

Manuel Antônio Chagas

JACINTO $^{5}$

Ariosvaldo Nunes de

MEDEIROS ${ }^{3}$

\section{Correspondência para:}

MARIA AUXILIADORA DE B. L. DAL MONTE

Curso de Doutorado em Engenharia de Processos

Centro de Ciências de Tecnologia da UFCG

Rua Aprígio Veloso, 882 - Bodocongó 58109-970 - Campina Grande - PB

britolira@bol.com.br

Recebido para publicação: 25/032003 Aprovado para publicação: 15/03/2005

\title{
Avaliação histológica de peles de caprinos em idades diferenciadas
}

\author{
1- CCT/UFCG, Campus de Campina Grande - PB \\ 2- Departamento de Agropecuária do CFT/UFPB, Campus de Bananeiras - PB \\ 3- Departamento de Morfologia do CCS/UFPB, Campus de João Pessoa - PB \\ 4- Departamento de Ciências Básicas da Saúde do CCBS/UFPB, Campus de \\ Campina Grande - PB \\ 5- Pesquisador do IPT, Franca - SP
}

\section{Resumo}

Palavras-chave: Pele (histologia).

Objetivando-se analisar a pele de caprinos, identificando as Caprinos. diferenças estruturais histológicas, utilizou-se 16 animais machos mestiços da raça Alpina, com 4 animais em cada abate a partir dos 180 dias com intervalos entre cada abate de 45 dias. Após o sacrifício foram retiradas amostras de pele das regiões dorsal, paleta, ventre, anca e lateral. Estas amostras foram fixadas em Bouin e processadas histologicamente segundo rotina de inclusão em parafina. Os cortes de $5 \mathrm{~mm}$ foram analisados e fotomicrografados. A pele dos caprinos, com 180 dias de vida, mostrou-se com maior espessura da camada termostática da derme, consequentemente com grande densidade de folículos e glândulas. Com o aumento da idade os feixes de fibras do colágeno se desenvolveram aumentando a espessura da camada reticular.

\section{Introdução}

Os caprinos possuem a pele revestida por pêlos finos, curtos e sedosos, a qual é superior às cobertas por pêlos longos, grossos e densos. No Brasil os caprinos de pêlos curtos produzem pele de boa qualidade, graças à resistência, à elasticidade e demais atributos nobres que apresentam. ${ }^{1}$

A pele ou tegumento, comum nos mamíferos, constitui uma barreira natural entre o meio externo do organismo animal e o meio ambiente, protegendo-o contra agentes físicos, químicos e microbianos. A pele consiste de duas camadas, a externa denominada epiderme, constituída por uma porção epitelial de revestimento, pavimentoso, estratificado e queratinizado de origem ectodérmica, e a interna formada por uma porção conjuntiva de origem mesodérmica, denominada derme. , $3,4,5^{2}$

A epiderme constitui a posição mais externa, composta por camadas a partir da superfície externa superior: a camada córnea, a lúcida, a granulosa, a espinosa e a basal. Por não possuir capilares, as substâncias nutritivas chegam até ela por difusão dos capilares existentes na derme..$^{5,6}$

As modificações que ocorrem na pele, com o decorrer da idade, dependem de vários componentes tissulares, as quais devem ser mais influenciadas por fatores tais como: o estado nutricional do animal e a exposição solar. O número de melanócitos diminui com a idade, pressupondo-se que esse fato esteja relacionado com o número de células basais circundantes. ${ }^{7}$

A espessura e a estrutura da epiderme da pele de caprino variam de acordo com o local estudado, ficando em torno de $1 \%$. Esta camada é mais espessa na região dorsal e mais delgada nos flancos. ${ }^{8}$

A derme é formada por fibras de tecido conjuntivo: colágenas, elásticas e reticulares, dividida em duas camadas, uma superficial denominada papilar ou termostática, está em contato com a epiderme. Esta camada é mais 
larga em animais herbívoros do que nos carnívoros, abrangendo os folículos pilosos, glândulas sudoríparas, glândulas sebáceas e músculo eretor do pêlo., A camada subjacente, que é denominada reticular por ser formada de feixes de fibras de colágeno em arranjo tridimensional entrelaçada por fibras elásticas ${ }^{5,10,11,12}$, há menos células do tecido conjuntivo na camada profunda do que na camada superficial ${ }^{3}$.

A hipoderme é constituída por tecido conjuntivo frouxo, que une a derme aos órgãos subjacentes. É a camada responsável pelo deslizamento da pele sobre as estruturas na qual se apoiam, a camada subcutânea é penetrada em todos os lugares por grandes vasos sangüíneos e terminações nervosas contribuindo com aproximadamente $5 \%$ da espessura da pele fresca (in vitro). ${ }^{13,14}$

No tegumento dos mamíferos, o colágeno é o constituinte estrutural mais abundante da derme, compreendendo cerca de 3/4 do peso seco. A habilidade do pêlo em resistir às solicitações mecânicas de tensão e de pressão resulta do arranjo e da intensidade de fusão das fibras e feixes de fibras formados por esta escleroproteína. ${ }^{15}$

A pele de caprino apresenta o entrelaçamento das fibras de colágenos mais espessas do que a de ovino e menos espessa do que a de bezerro, principalmente na região do grupão. A camada papilar ou termostática ocupa a metade da espessura final total da pele, o número de glândulas sebáceas é muito inferior às de ovino, e o músculo eretor do pêlo nos caprinos é bem desenvolvido. Em geral, as fibras colágenas da camada reticular se distribuem horizontalmente. Devido a sua própria estrutura algumas propriedades do couro são dadas pelo estado da camada termostática, a exemplo da aparência. ${ }^{16}$

Diante dessas considerações, esse trabalho tem o objetivo de avaliar histologicamente peles de caprinos em idades diferenciadas.

\section{Materiais e Métodos}

Foram utilizados caprinos mestiços
Alpinos, provenientes do rebanho do setor de caprinocultura do Centro de Formação de Tecnólogos - Campus IV da UFPB, localizado no município de Bananeiras-PB.

Foram utilizados dezesseis animais do sexo masculino. Os animais foram sacrificados em intervalos de 45 dias, sendo o primeiro aos 180 dias de idade, o segundo aos 225 dias, o terceiro aos 270 dias e o último aos 315 dias de vida. Os abates ocorreram no abatedouro escola do Centro de Formação de Tecnólogos.

As amostras para os cortes histológicos foram colhidas nas regiões: dorsal, lateral, ventral, anca e paleta, do lado esquerdo da pele, logo após o abate e esfola dos animais, como indicado na figura 1 , com a ajuda de uma trefina de seção retangular, medindo $1,0 \mathrm{~cm}$ de comprimento por 0,5 cm de largura. ${ }^{17,18}$

As amostras foram fixadas em solução de Bouin por 48 horas, em vidros identificados com etiquetas auto-adesivas contendo as informações necessárias: animal, idade, região (local da pele no qual foi retirada a amostra), direção relacionada ao eixo e data.

As amostras foram processadas, histologicamente, segundo rotina de inclusão em parafina. ${ }^{19}$

Os cortes corados foram novamente desidratados em série alcóolica, passando ao xilol e depois montados com resina sintética e cobertos com lamínula. ${ }^{2,3,12}$

A análise da matriz extracelular foi feita através da observação dos cortes histológicos em microscopia fotônica,

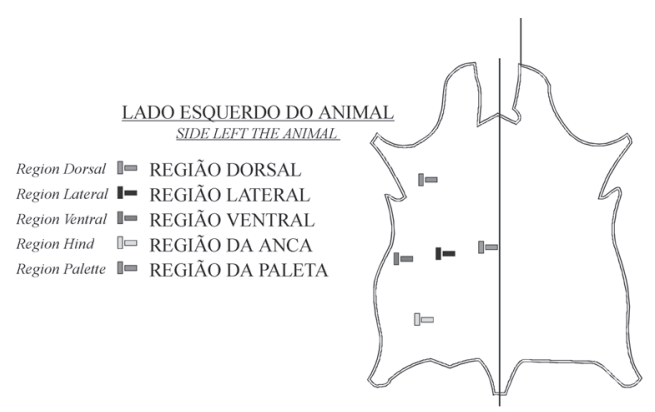

Figura 1 - Regiões da pele coletadas para os cortes histológicos na direção perpendicular e paralela ao eixo (x). 
utilizando como referência as características próprias dos feixes de fibras de colágeno.,

A verificação da espessura das camada termostática e reticular nas quatro idades foi feita através de uma escala existente em um retículo ocular previamente calibrado com uma lâmina micrométrica.

A avaliação comparativa das glândulas sudoríparas e sebáceas, como também do folículo piloso, foi efetuada através de fotomicrografia ${ }^{21,22,23}$, usando-se um fotomicroscópio "Karl Zeiss" de polarização.

\section{Resultados e Discussão}

Através deste estudo verificou-se que a epiderme apresenta a camada córnea e o extrato disjuncto, estruturas observadas por Kozlowski e Calhoun ${ }^{24}$ em ovinos, Araújo ${ }^{25}$ em bovinos e Jacinto ${ }^{22}$ em ovinos lanados. Essas estruturas são responsáveis pela impermeabilidade da pele (Figura 2) e são eliminadas na primeira etapa do processo de curtimento.

Segundo Calhoun e Stinson ${ }^{3}$, em caprinos, os folículos pilosos apresentam-se como primários e secundários, variando com a idade e a região da pele. $\mathrm{O}$ folículo primário é de grande diâmetro, apresenta-se implantado profundamente na derme e, normalmente, associado às glândulas sebáceas, às sudoríparas e a um músculo eretor. $\mathrm{O}$ folículo secundário possui diâmetro menor do que o do primário e a sua raiz está próxima da superfície. Ele pode possuir uma glândula sebácea, mas não possuir glândulas sudoríparas e músculo eretor.

Através deste estudo observaram-se diferenças acentuadas entre as peles dos animais nas diferentes idades: 180, 225, 270 e 315 dias de vida. Quanto à espessura das camadas que compõe a derme, observou-se que a camada papilar ou termostática é mais espessa nos animais de 180 dias de vida, representando mais da metade da espessura total da pele, com grande número de folículos pilosos por unidade de área e elevada relação entre os folículos secundários e primários, glândulas sudoríparas e sebáceas.

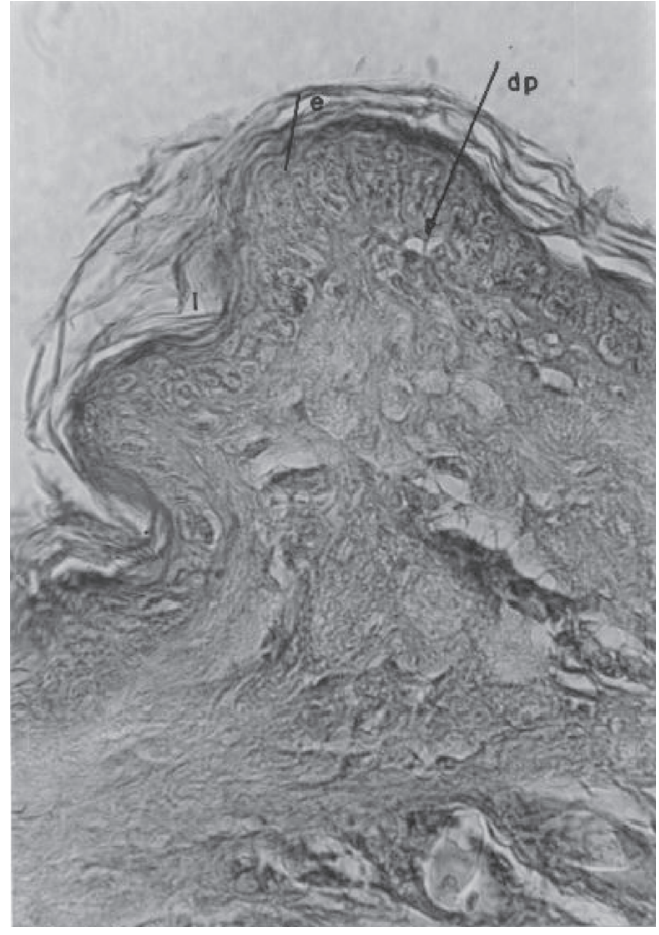

Figura 2 - Fotomicrografia da epiderme (e) do tegumento de caprino mestiço Alpino mostrando a camada córnea (1) e a derme papilar (dp). H \& E. 500x

Avaliando-se as análises morfológicas da pele, a identificação das camadas papilar ou termostática e reticular dos caprinos foi possível por fotomicrografias obtidas com microscopia fotônica, sem polarização da luz (Figuras 3 e 4). Esse método também foi utilizado por Hoinacki. ${ }^{16}$

A camada papilar ou termostática diminuiu com o aumento da idade, conseqüentemente diminuiu o número de folículos, glândulas sebáceas e sudoríparas. Warren, James e Neville ${ }^{26}$ também observaram que o número e a área de distribuição de glândulas sebáceas, em tegumento comum de ovinos, diminuiu com o aumento da idade.

Grande parte da fisiologia da pele está ligada ao desempenho dessas estruturas, das terminações nervosas, dos capilares sangüíneos e hormônios, sendo assim denominada termostática por ter função termo-reguladora. Araújo ${ }^{25}$, comparando o tegumento de bovinos com seis meses e um ano de vida, 


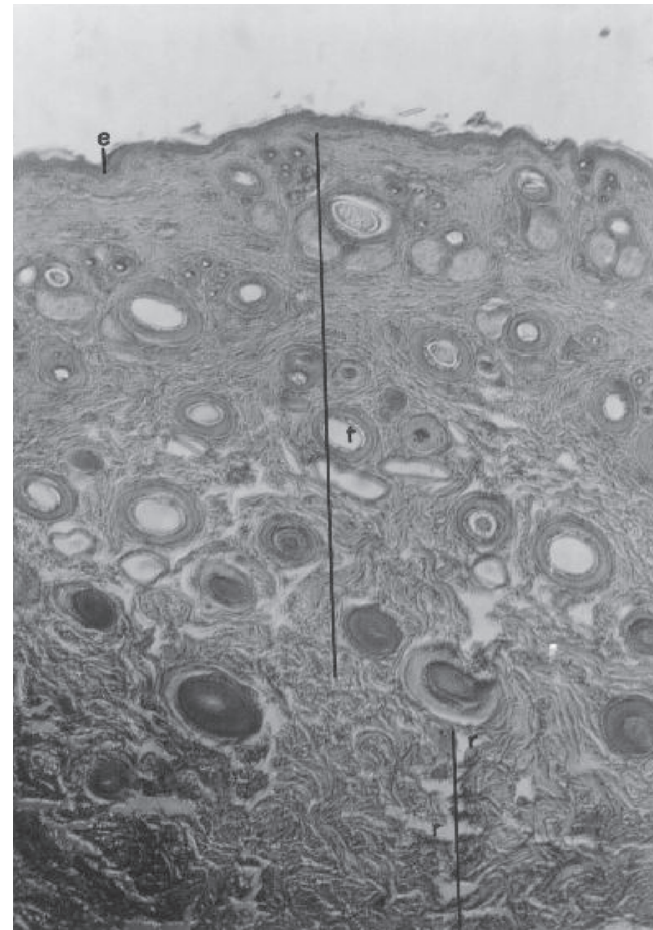

Figura 3 - Fotomicrografia do tegumento de caprino mestiço Alpino de 180 dias, região dorsal, mostrando a camada termostática (t), a camada reticular (r) e a camada epidérmica (e). H \& E. 200x

observou uma pequena queda na quantidade de folículos pilosos aos seis meses.

Associados aos folículos primários são encontrados os folículos secundários, o músculo eretor do pêlo, glândulas sudoríparas e glândulas sebáceas (Figuras 5 e 6 ).

Em ovinos, os folículos pilosos apresentam-se organizados em grupos e em número variável, dependendo da raça e região da pele. $^{23}$

As glândulas sebáceas, nas quatro idades estudadas, estão localizadas no terço superior dos folículos pilosos, sendo normalmente bilobuladas. Entre as glândulas sebáceas, o folículo piloso primário e o músculo eretor do pêlo identificou-se a abertura do ducto da glândula sudorípara, estrutura já observada por Jacinto ${ }^{23}$, quando estudou a pele de ovinos Morada Nova, de 1 ano de idade.

No que tange ao número de glândulas sebáceas em bovinos, Araújo ${ }^{25}$ constatou de modo similar às nossas observações, que o

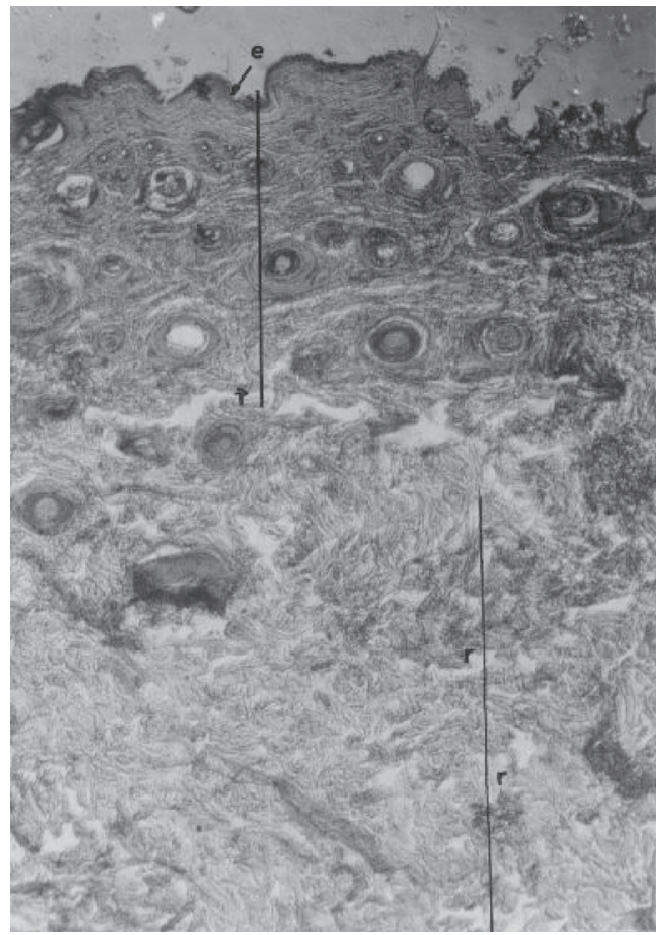

Figura 4 - Fotomicrografia do tegumento de caprino mestiço Alpino de 315 dias, região da paleta, caracterizando a camada termostática (t), a camada reticular (r) e a camada epidérmica (e). H \& E. 200x

número e a área de distribuição diminui com a idade.

O folículo está mergulhado na derme normalmente em ângulo, e o bulbo pode estender-se tão profundamente que pode alcançar a camada reticular. Após um período de crescimento durante o qual o pêlo atinge o crescimento máximo, as células germinativas cessam sua atividade, e o folículo entra em repouso. Logo após esta fase, um novo pêlo cresce e a raiz do antigo pêlo se desloca no sentido da superfície (Figura 7).

O músculo eretor do pêlo, composto por feixes de fibras musculares lisas, prendese a bainha conjuntiva do folículo piloso, na sua porção mediana e na camada papilar ou termostática, próximo a superfície da pele. $\mathrm{O}$ músculo, do mesmo modo que a glândula sebácea, situa-se ao lado do folículo que forma ângulo obtuso com a superfície da pele. ${ }^{4}$

A profundidade dos folículos é proporcional à espessura dos pêlos que os folículos produzem. Em relação ao tamanho, 


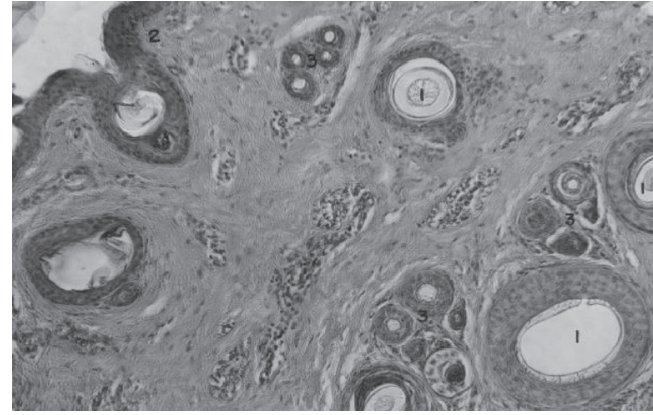

Figura 5 - Fotomicrografia do tegumento de caprino de 225 dias de idade, região da paleta mostrando os folículos primários (1), a papila dérmica (2) e os folículos secundários (3). H \& E. 500x

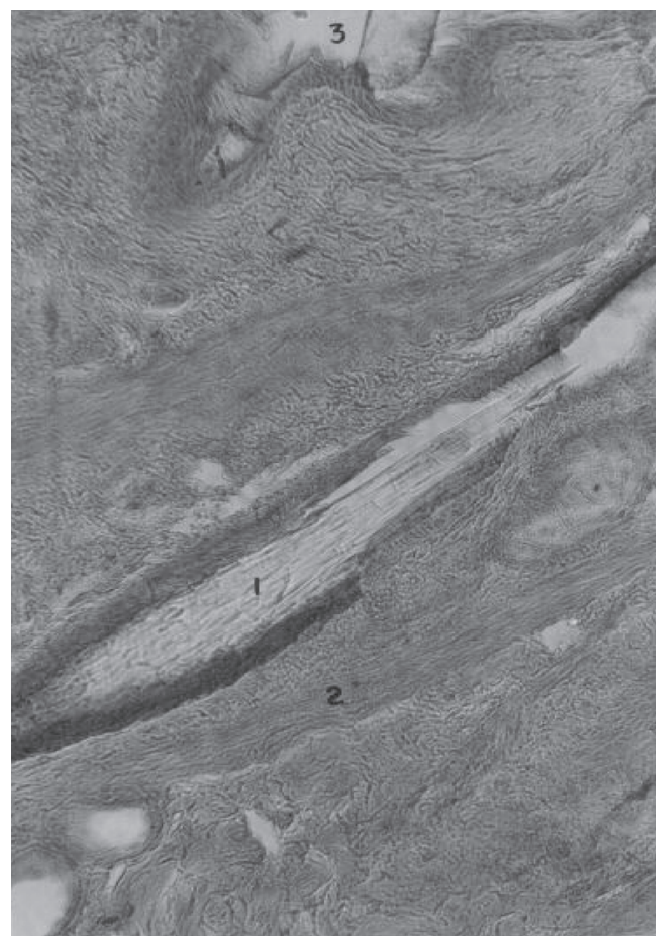

Figura 7 - Fotomicrografia do tegumento de caprino aos 315 dias de idade, região da anca, mostrando um grande pêlo primário estendendo-se para a superfície (1), músculo eretor do pêlo (2) e epiderme (3). H \& E. 500x

somente uma pequena parte do folículo ativo, a matriz, produz células que formam o pêlo. Quando os folículos deixam de produzir pêlo, o bulbo desaparece, a estrutura se modifica e o folículo entra em período de total quiescência. Quando se tornam ativos outra vez, precisam

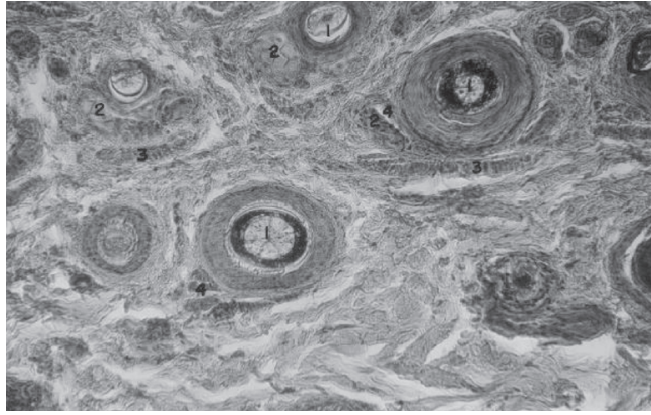

Figura 6 - Fotomicrografia do tegumento de caprino com 225 dias de idade, região lateral, mostrando o pêlo dentro do folículo piloso (1), as glândulas sebáceas (2), o músculo eretor do pêlo (3) e o ducto da glândula sudorípara (4). H \& E. 500x

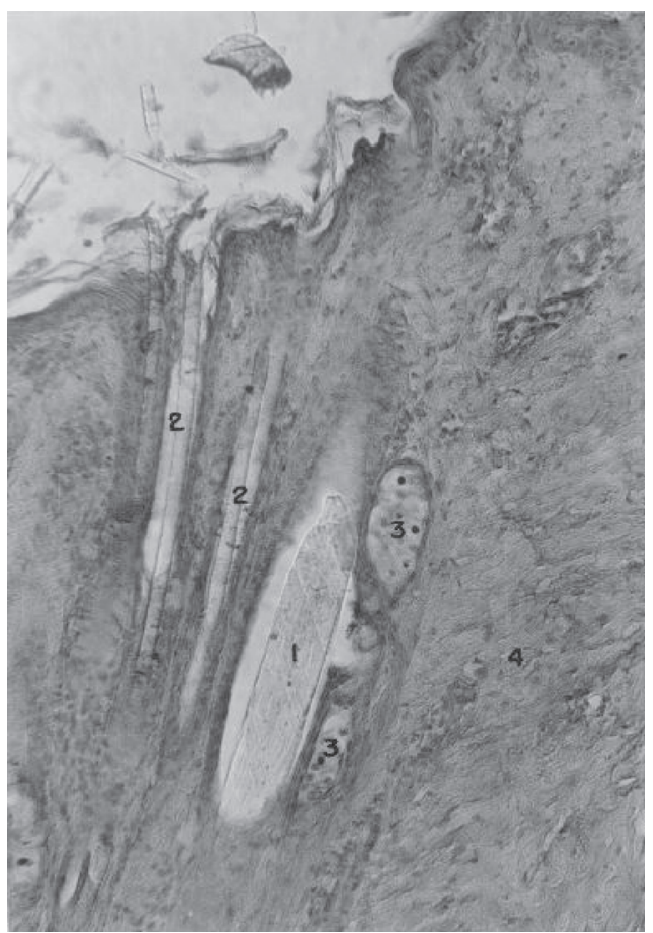

Figura 8 - Fotomicrografia do tegumento de caprino aos 270 dias, região da paleta, observa-se um pêlo dentro do folículo piloso primário (1), folículos secundários (2), glândulas sebáceas (3) e feixe de fibras de colágeno (4). H \& E. 300x

reconstruir um folículo, seguindo os mesmos processos morfogenéticos (Figura 8).

A espessura total das peles dos caprinos variou proporcionalmente às idades, apresentando, inclusive, diferenças significativas entre os animais mais jovens (180 
dias) e os animais mais velhos (315 dias).

Em relação à medida da espessura das camadas que formam a derme, a camada papilar ou termostática apresentou-se maior nos animais mais jovens, porém apresentou praticamente a mesma espessura entre as regiões estudadas. Conseqüentemente, houve uma tendência dos animais mais velhos apresentarem maior resistência aos testes físicomecânicos de controle de qualidade do couro, visto que a camada reticular é composta por fibras de elastina e colágeno, desenvolvendose cada vez mais ao longo do tempo.

\section{Conclusões}

As observações dos cortes histológicos das peles de caprinos mestiços
Alpinoso, nas quatro idades estudadas, mostram que a epiderme é um tecido que sofre diferenciação. As células estratificadas representam o estágio final do processo e as células localizadas profundamente, os estágios iniciais. A derme dos caprinos, em idades diferenciadas, também apresenta as camadas sem limite definido entre si: papilar ou termostática e a reticular.

Nas peles de caprinos de 315 dias a camada reticular da derme é mais espessa do que nos animais jovens. Os folículos primários e os secundários, também se apresentam, porém somente nos primários foram associados o músculo eretor do pêlo, glândulas sudoríporas e glândulas sebáceas. A análise dos cortes histológicos permitiu identificar que a camada papilar ou termostática é mais espessa nos animais mais jovens (180 dias).

\section{Histological evaluation of goat's hair at different ages}

\section{Abstract}

Key-words:

The objective of theis research was to analyze the skin of goats, Skin. identifying the structural differences in the cell level. It was used 16 animals, males, crossbred Alpine, using 4 animals in each slaughter, at the age of 180 days and older, used intervals of 45 days between each slaughter. After flaying the animals, it was removed samples of the skin from dorsal, palette, ventral, hind and lateral regions. These samples were placed in a Bouin solution an analyzed at cellular level, according to the paraffin inclusion routine. The $5 \mathrm{~mm}$ cuts were photomicrographed and analyzed. The goats skin that were 180 days old shown a thicker thermostatic layer of the skin, consequently with a greater density of follicles and glands. With age the reticular layer develops leading to the sheaves of fibers of the collagen.

\section{Referências}

1 JARDIM, W. R. Criação de caprinos. 11aㅡ ed. São Paulo: Nobel, 1984. 353 p.

2 HAM, A. W. Interpretação dos cortes ao microscópio; Problemas e processos no estudo e na identificação dos cortes no laboratório; In: Histologia. 6. ed. Rio de Janeiro: Guanabara Koogan, 1972. p. 9-49.

3 CALHOUN, M. L.; STINSON, A. W. Tegumento. In: DELLMANN, H. D.; BROWN, E. M. Histologia veterinária. Rio de Janeiro: Guanabara Koogan, 1982. p. 360-387.
4 HAM, A. W. Sistema tegumentar. In: Histologia. 6. ed. Rio de Janeiro: Guanabara Koogan, 1983. p. 595-622.

5 JUNQUEIRA, L. C.; CARNEIRO, J. Pele e anexos. In: . Histologia básica. Rio de Janeiro: Guanabara Koogan, 1995. p. 271-280.

6 JENKINSON, D. M. E.; MONTGOMERY, I.; ELDER, $\mathrm{H}$. Y. The ultrastructure of the sweat glands of the ox, sheep and goat during sweating and recovery. J. Anat., Glasgow, v. 129, p. 117-140, 1979. 
7 FITZPATRICK, T. B.; SZABO, G.; MITCHELL, R. E. Age changes in the human melanocyte system. Advanc. Biol. Skin, G, v. 6, p. 35, 1964.

8 LYNE, A. G.; HOLLIS, D. E. The skin of the sheep: a comparison of body regions. Aust. J. Biol. Sci., v. 21, p. 499-527, 1968.

9 WEINER, J. S.; HELLMANN, K. The sweat glands. Biol. Rev. Camb. Phil. Soc., v. 35, p. 141-186, 1960.

10 GIBSON, T.; KENEDI, R. M.; CRAIK, J. E. The mobile micro-architecture of dermal collagen. Br. J. Surg., v. 52, p. 764-770, 1965.

11 SZIRNAI, J. A. The organization of the dermis. Adv. Biol. Skin, v. 10, p. 1-17, 1970.

12 BLOOM, W.; FAWCETT, DON. W. Pele. In: . Tratado de histologia. 10 ed. Rio de Janeiro: Interamericana, 1977. p. 514-546.

13 STANLEY, L.; ROBLINS, M. B. Patologia 2. ed. Rio de Janeiro : Guanabara Koogan, 1969. p. 1263-1267.

14 HOINACKI, E.; MOREIRA, M. V.; KIEFER, C. G. Manual básico de processamento de couro. Porto Alegre: CPF SENAI de Artes Gráficas, 1994. 420 p.

15 MATHEWS, M. B. Conective lissue, macromolecular estruture and evolution, molecular biology, biochemistry and biophysics. New York: Springer, 1975. v. 19.

16 HOINACKI, E. Peles e couros 2. ed. Porto Alegre: CPF de Artes Gráficas, 1989. 320 p.

17 CARTER, H. B.; DOWLING, D. F. The hair follicle and apocrine gland population of cattle skin. Aust. J. agric. Res., v. 5, n. 4, p. 745-757, 1955.

18 NAY, T. Technique for examining wool follicles in the skin of sheep. Australian Wool Corporation, Melbourne, 1973.

19 JUNQUEIRA, L. C.; JUNQUEIRA, L. M. S. Técnicas básicas de citologia e histologia. São Paulo: Santos, 1983. p. 123.

20 VIDAL, B. C.; MELO, M. L. S. Biologia celular. São Paulo: Livraria Atheneu, 1987. 347 p.

21 WALKER, M. I. Fotomicrografia. Barcelona: Omega, 1973. $207 \mathrm{p}$.

22 JACINTO, M. A. C. Fotomicrografia. Ribeirão Preto: Faculdade de Medicina, USP, 1986. 26 p. Monografia.

23 JACINTO, M. A. C. Características anátomoestruturais da pele e do couro de ovinos lanados e deslanados. 1996. 92 f. Dissertação (Mestrado em Zootecnia) - Faculdade de Ciências Agrárias e Veterinárias, UNESP, Jaboticabal, 1996.

24 KOZLOWSKI, G. P.; CALHOUN, M. L. Microscopic Anatomy of the integument of sheep. An. J. Vet. Res., Schaumburg, v. 30, n. 8, p. 1267-1279, 1969.

25 ARAÚJO, M. L. Contribuição ao estudo morfológico do tegumento de bovinos das raças Holandês preto $\mathrm{e}$ branco e Jersey. 1990. 109 f. Tese (Doutorado em Morfologia)Botucatu, Instituto de Biociências, Universidade Estadual Paulista de Botucatu, Botucatu, 1990.

26 WARREN, G. H.; JAMES, P. J.; NEVILLE, A. M. A morphometric analysis of the changer with age in the skin surface wax and the sebaceaus gland area of Merino sheep. Aust. Vet. J., v. 60, p. 238-240, 1983.

27 WAITES, G. M. H.; VOGLMAYR, J. K. Apocrine sweat glands of the scrotum of the ram. Nature, Lond., v. 196, p. 965-967, 1962. 